SIV-1a

\title{
Construction of PV Systems for Elementary Schools in the Savannah of Togo
}

\section{Light for Education and Culture}

\section{Etienne Dable ${ }^{1}$}

\section{Background}

The savannah region in northern Togo borders on Ghana, Burkina Faso and Benin (Figure 1). It covers $8,596 \mathrm{~km} 2$, which is $15 \%$ of the total area of Togo. The regional capital Dapaong has about 100,000 inhabitants. The savannah region consists of 5 prefectures, 70 cantons, 1,073 villages and 451 hamlets. The number of inhabitants is growing rapidly. The population figures were 828,224 in 2010 and 890,403 in 2013, a growth rate of $8.2 \%$ in only 3 years. With 105 inhabitants per km2 the savannah region is more densely populated than German MecklenburgVorpommern (69 inhabitants per km2).

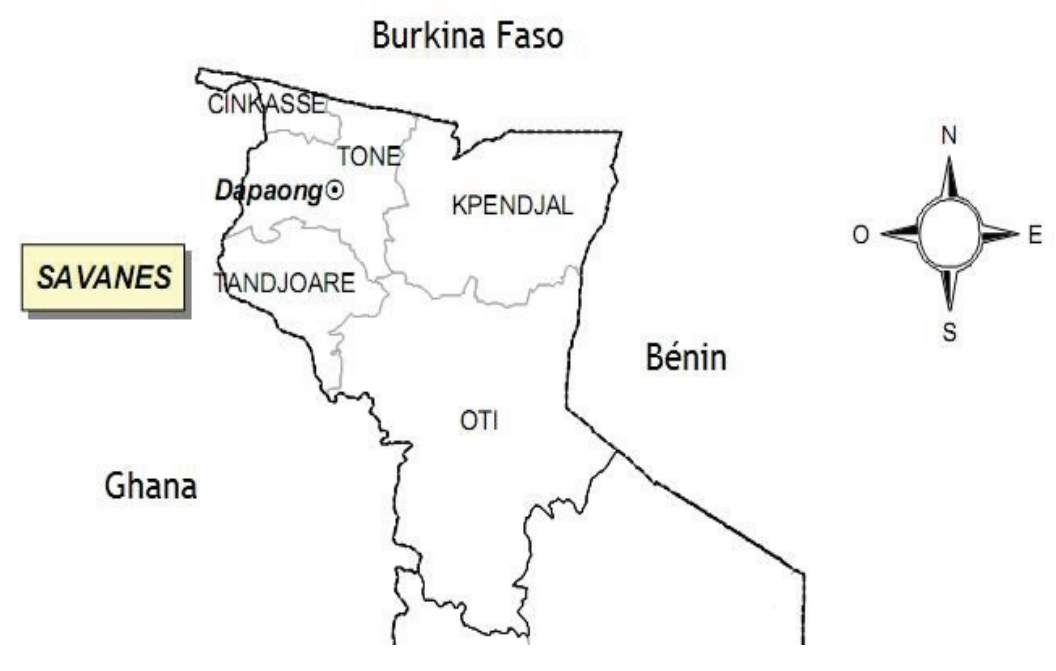

Figure 1: Region of Savannah

The savannah region is the poorest region in the country. In the villages, subsistence farming prevails. Surpluses are sold at village markets or nearby city markets with little profit, since raw products are rarely processed and certainly not processed and the purchasing power in the region is low. The sensitive savannah floors are overused. During the long dry season (October to May) there is a lack of artificial irrigation. The climate change affects the savannah region through shorter and irregular rainy seasons. Deforestation leads to further drying out of the soil. The population is increasing, becoming poorer and poorer and uses almost exclusively wood for cooking in the villages. This leads to further deterioration of the arable land. Harvest yields

\footnotetext{
${ }^{1}$ Dipl.-Ing. Etienne Dable, IT Village, Dapaong
} 
are falling because improved seeds and fertilisers are also lacking. The infrastructure in the region is at an extremely low level. There are no industrial enterprises in the savannah region. There is an almost complete lack of companies that process and refine agricultural products. There is a lack of storage facilities and cold chains for agricultural products. Only for wood and charcoal there are transport routes from the international highway to regions with better purchasing power. A major obstacle to the establishment of small businesses is the lack of electricity.

\section{Bonita-Haus and IT Village}

Dapaong is the capital of the savannah region and the northernmost city of Togo. It is the seat of the IT VILLAGE association and since 2013 the first modern private educational centre for vocational and technical training of young people in the savannah, which was built by IT Village with the support of DAZ e.V. - the Bonita-Haus (Figure 2). IT Village now trains 120 young men and women from Togo and Burkina Faso in this educational facility. The training and studies focus on new technologies, agroecology, handicrafts as well as commercial and economic fields of expertise, for which there is a need in the region and which are important for its economic development.
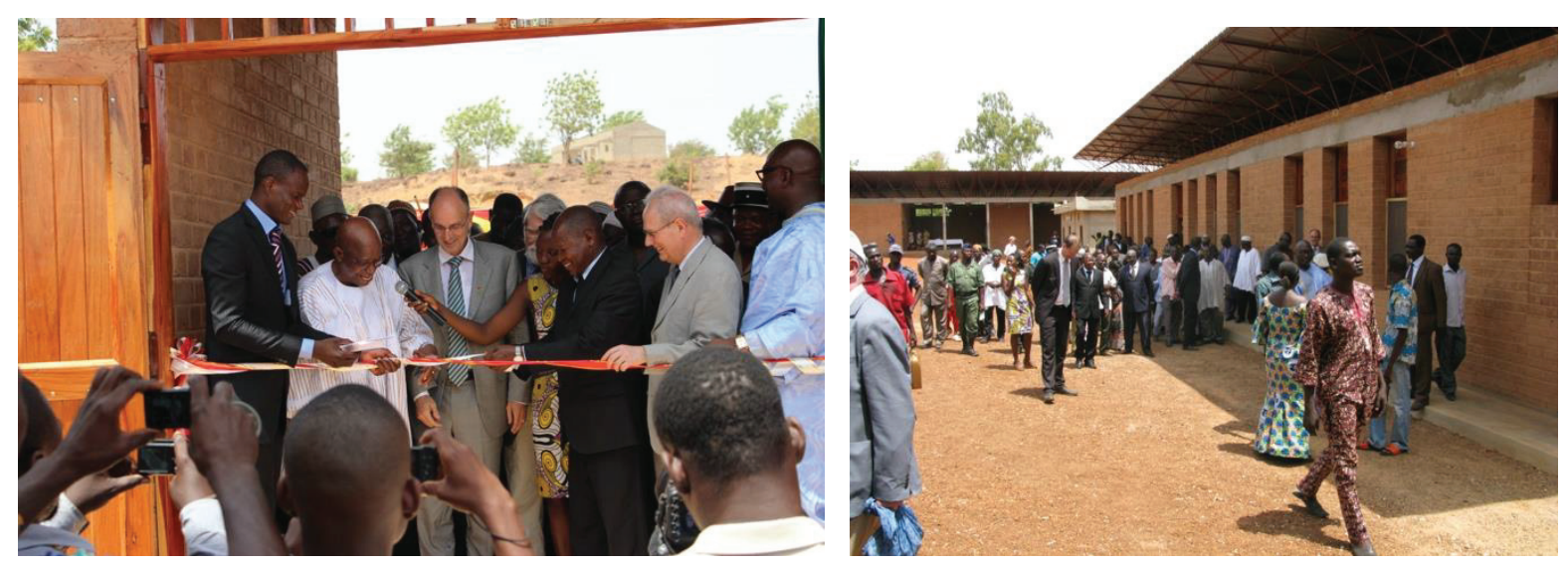

Figure 2: Opening of Bonita-Haus in March 2013

In the past, the Bonita-Haus and the DAZ have created the basis for supporting sustainable development with renewable energy systems. In addition to stationary systems, a development project "Human and Technics - mobile regenerative energy systems in the savannah for life and education" has been carried out in 2016 , which can now supply demonstrators for PV systems [1].

Within the framework of active workshops, a mobile PV system was set up with professional school students from various disciplines. The spectrum of professions represented ranged from electrical engineer to welder and car mechanic. The knowledge-hungry and highly motivated vocational students were supervised during the workshop by the three engineers from the Technical University of Applied Sciences Wildau René von Lipinski, Uwe Düsterhaus and Sebastian Schulz (Figure 3). They were actively supported by the local engineer Samuel Yao Wodou, the interpreter Elias Harakawa from Lomé and the electrical engineer Kankpiame Sissob from BONITA Haus. 


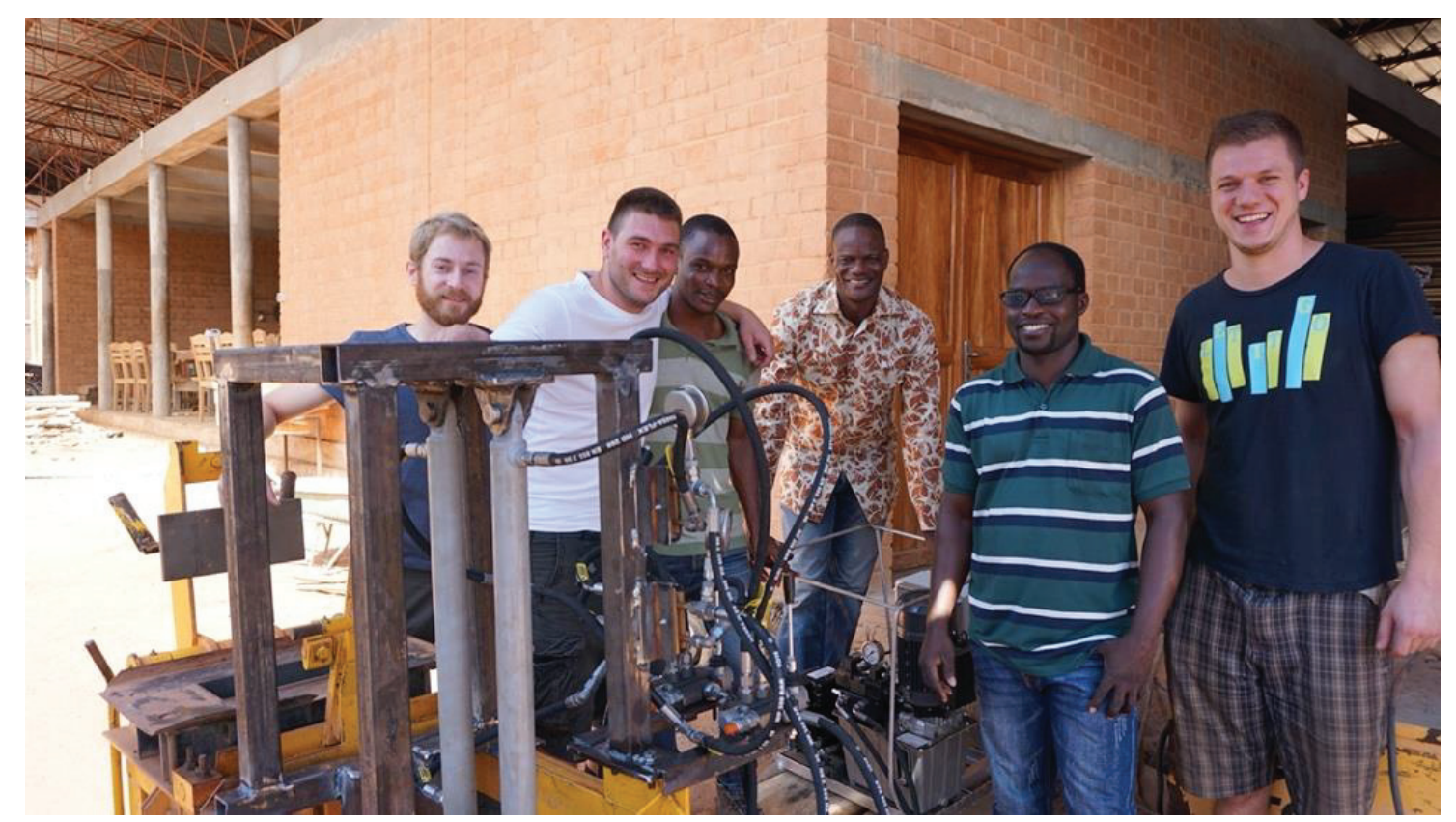

Figure 3: Brick machine driven with renewable energies

Nowadays, DAZ and IT Village support five primary schools in villages in the savannah. At present about 2,000 students attend these schools. By improving school teaching, the number of pupils attending the 6th grade could be increased from 89 to 298 from school year 2010/11 to school year 2015/16. This has been achieved by:

- Establishment of libraries,

- Equipping 500 pupils from poor families with teaching materials,

- Reduction of school classes by taking over the salary of 26 additional teachers,

- School lunch,

- Construction of 6 school buildings with solar panels.

The solar systems allow the school buildings to be used in the evening hours as well. It is also used to recharge mobile phones and operate refrigerators for school meals. Further school buildings with solar systems are in planning.

\section{Concept for decentralized power supply}

In 2014 the DAZ in cooperation with IT Village started the electrification of the schools Nagre II, Kourdjoak and Mandime in the savannah by means of solar technology (Figure 4). This system will be used for lighting the classrooms and cooling for the school lunch for the children and will be provided to the residents as a reference for light and electricity. The solar systems have been in operation since 2014 and are stable in operation. What all plants and systems have in common is that they are operated as stationary systems and are not mobile.

In the construction of the BONITA House training centre in Dapaong and the school extension buildings in Nagre II, Kourdjoak and Mandime, architect Francis Kéré from Burkino Faso used adobe construction methods for the first time in the savannah and in Togo. An alternative would have been the concrete construction method. In comparison, the clay construction method offers optimal climatic conditions due to the cool room temperatures, especially in the hot dry season, 
and thus enables more concentrated learning and working for students and teachers. Clay bricks are not available on the market and there was and is no alternative machine to the clay brick press in the region. Therefore, the manually operated press was also bought in Belgium in 2010 - it was the only offer DAZ received after extensive research and rebuild with an electrical propulsion system in 2016 (see Figure 3).
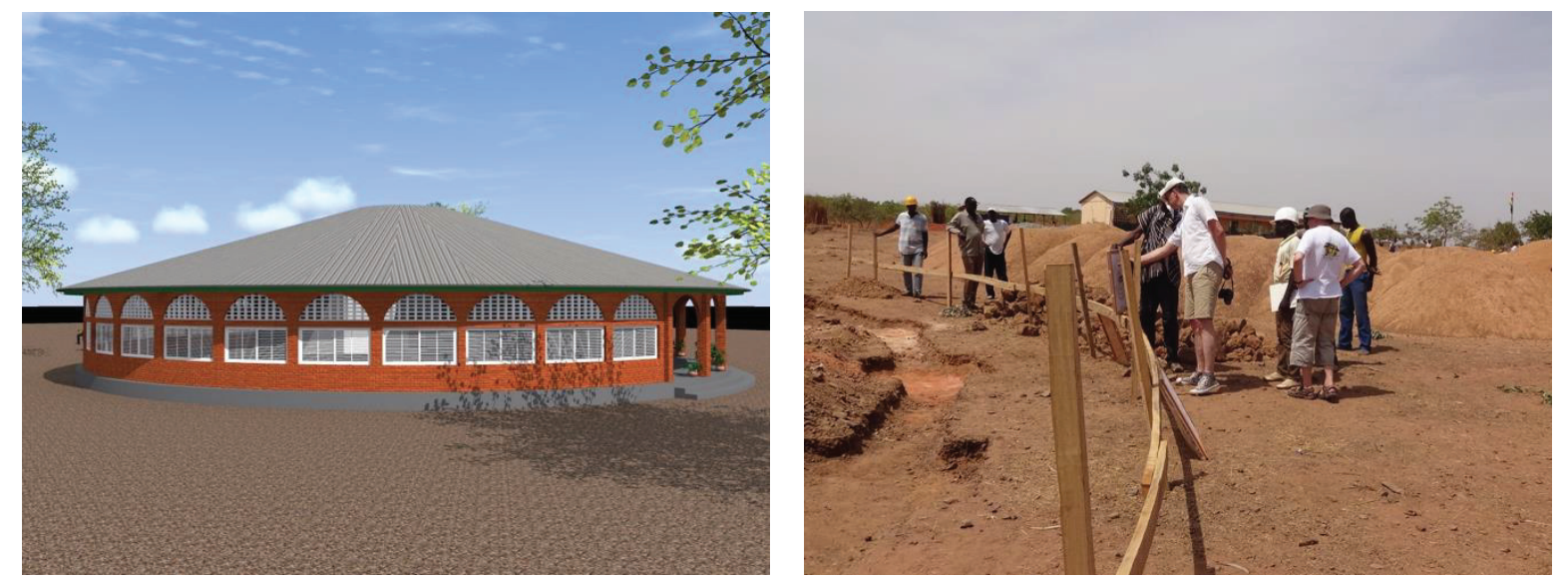

Figure 4: Construction area for new school including canteen

In addition with the stationary energy supply at schools (Figure 5), this mobile demonstrator is a good starting point for demonstrating the use of renewable energies. Especially applications of photovoltaics show a great potential for the Sub-Sahara region. Equipping schools with decentralized energy systems gives pupils and teachers the chance for continuous education.

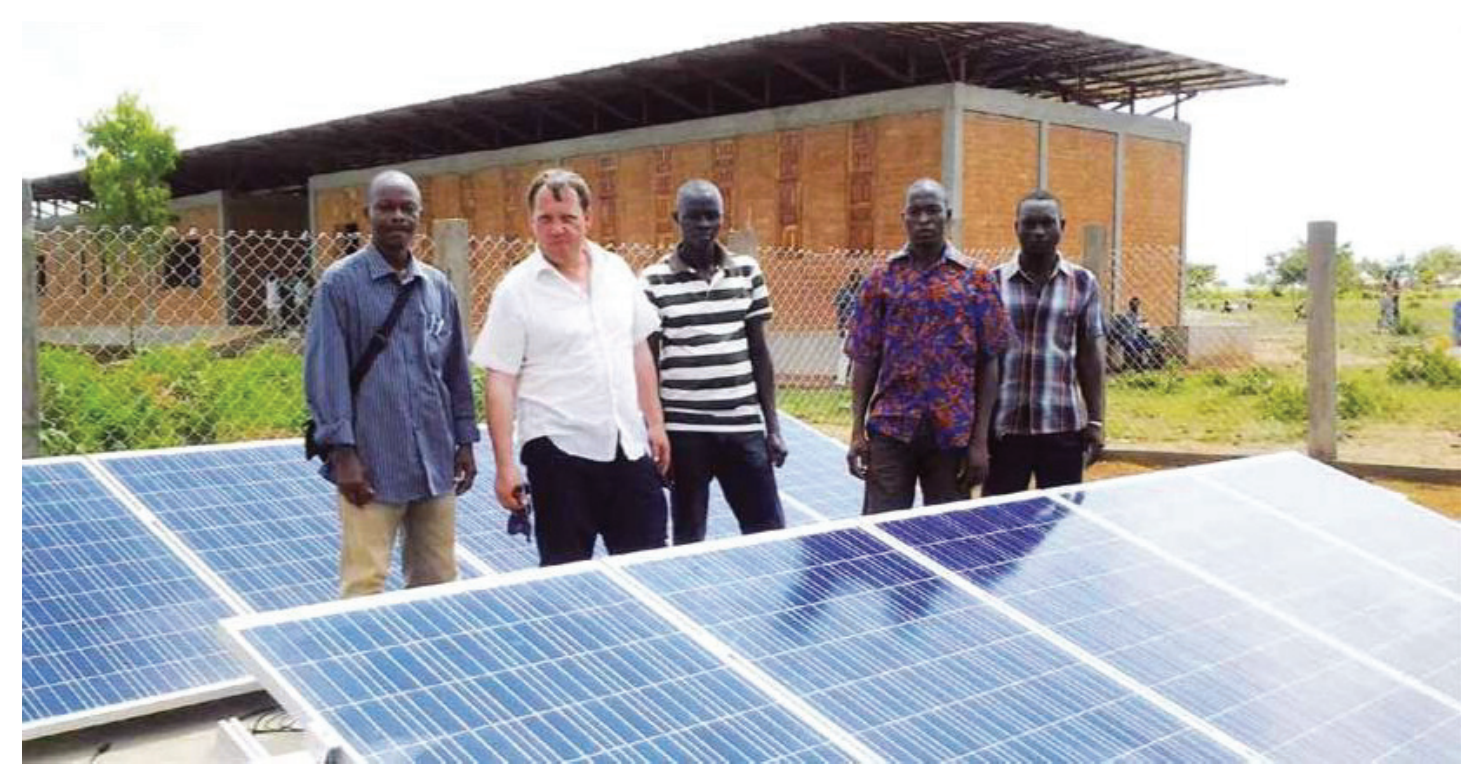

Figure 5: Stationary PV-System

\section{Conclusion and Outlook}

The BONITA-Haus, IT Village, DAZ and the Technical University of Wildau near Berlin are in deep collaboration since years. This will be extended to the State Universities in Kara and Lomé. 
For more than three decades, TH Wildau has been dealing with the use of regenerative energies for application in industrialised and social environments. One topic is the utilization of these energies for regions with non-centralized energy supply. This topic should be the focus of the cooperation between TH Wildau and the Togolese training centres in Dapaong and the Center of Renewable Energy Systems in Kara.

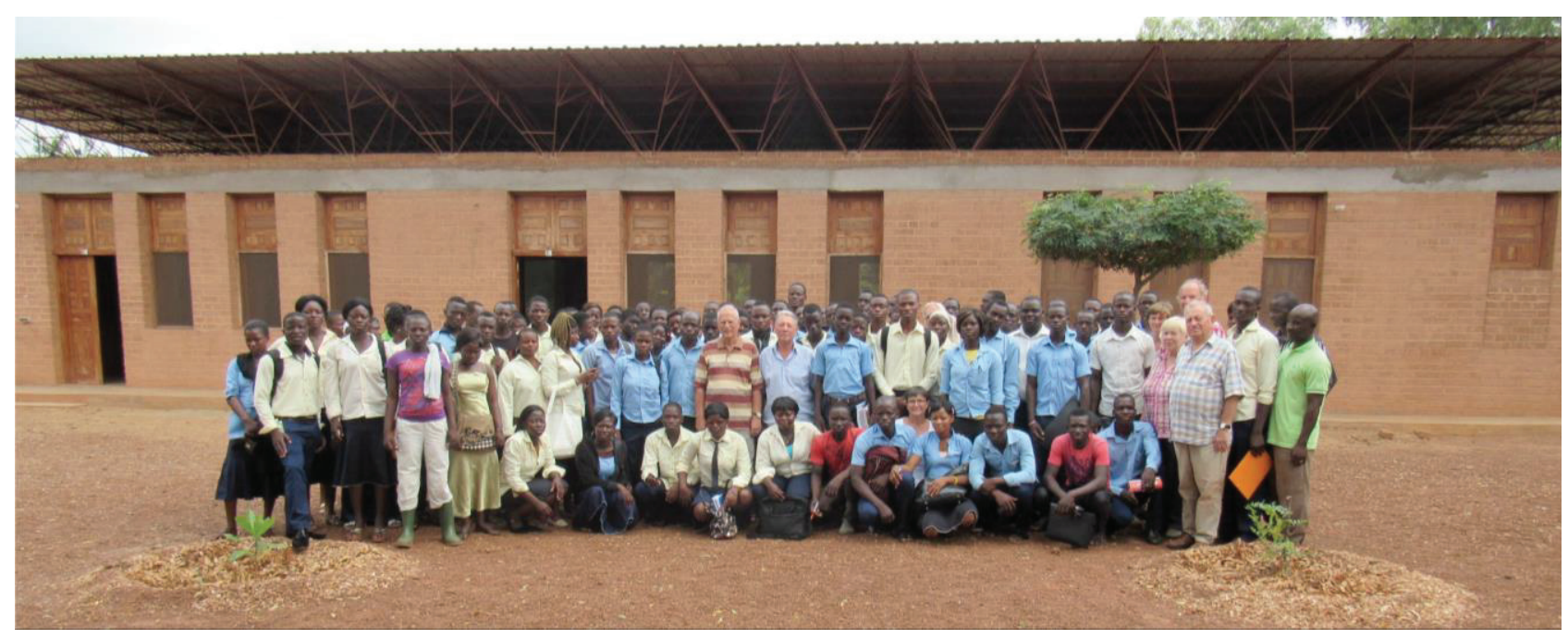

Figure 6: Bonita-Haus's students of Agroecology during the visit of DAZ members in 2016

For all future tasks, a reliable energy supply must be created for the participating companies in Togo and the sub-Saharan region. This requires cooperation in a centre to share knowledge and experience. The use of renewable energies can be created here as an example for the application in regions with non-centralized energy supply. This is a central requirement for the creation of jobs in the rural regions of Africa. Because "Energy poverty is ... synonymous with poverty, because without electricity there is no light for learning, no computer running and no machine to help run small businesses" [4].

\section{Acknowledgments}

The research was partially supported by the German Federal Ministry for Economic Cooperation and Development (BMZ) (No: bengo6452). We are particularly grateful to our scientific partner TH Wildau for providing support in development as well as during the implementation phases.

\section{References}

[1] J. O. Löfken, „Afrika entdeckt die Sonne“. tr - Technology Review vol. 6, pp. 26-32, 2011

[2] D. Kohnert, "Togo". Africa Yearbook 2005 - Politics, economy and society South of the Sahara. Melber/Mehler/Walraven (eds.), Brill, Leiden \& Boston, in press, 2006

[3] J. Reiff-Stephan, "Solarkraft in der Produktentwicklung - Anwendungen für Westafrika," EEE-Techn. Design in Forschung, Lehre und Praxis, TUDPress, Dresden, 2014, pp. 327-340.

[4] F.Woellert and R. Klingholz, "Jobs für Afrika," BI discussion paper Berliner Institut für Bevölkerung und Entwicklung, ISBN: 978-3-946332-84-8, vol. 17, 2016 